\title{
BMJ Open How people with dementia and carers understand and react to social functioning changes in mild dementia: a UK-based qualitative study
}

David Singleton, ${ }^{1}$ Naaheed Mukadam, ${ }^{1,2}$ Gill Livingston, ${ }^{1,2}$ Andrew Sommerlad ${ }^{1,2}$

To cite: Singleton D, Mukadam N, Livingston G, et al. How people with dementia and carers understand and react to social functioning changes in mild dementia: a UK-based qualitative study. BMJ Open 2017;7:e016740. doi:10.1136/ bmjopen-2017-016740

- Prepublication history for this paper is available online. To view these files please visit the journal online (http://dx.doi org/10.1136/bmjopen-2017016740).

Received 7 March 2017 Revised 9 June 2017

Accepted 19 June 2017

CrossMark

${ }^{1}$ Division of Psychiatry, University College London, London, UK

${ }^{2}$ Camden and Islington NHS Foundation Trust, St Pancras Hospital, London, UK

Correspondence to Dr Andrew Sommerlad; a. sommerlad@ucl.ac.uk

\section{ABSTRACT}

Objectives To analyse people with dementia and their family carers' attribution of social changes in dementia and the consequences of these attributions.

Design Qualitative study, using a semi-structured interview guide. Individual interviews continued to theoretical saturation. Two researchers independently analysed interview transcripts.

Setting and participants People with mild dementia and family carers purposively selected from London-based memory services for diverse demographic characteristics to encompass a range of experiences.

Primary and secondary outcomes Attribution of social changes experienced by the person with dementia and the consequences of these attributions.

Results We interviewed nine people with dementia and nine carers, encompassing a range of age, ethnicity and educational backgrounds. Both groups reported that the person with dementia had changed socially. People with dementia tended to give one or two explanations for social change, but carers usually suggested several. People with dementia were often socially embarrassed or less interested in going out, and they or their relatives' physical illness or fear of falls led to reduced social activity. Carers often attributed not going out to a choice or premorbid personality. Carers found that their relative needed more support to go out than they could give and carers needed time to themselves because of carer stress or other problems from which they shielded the person with dementia. Additionally, there was decreased opportunity to socialise, as people were bereaved of friends and family. Participants acknowledged the direct impact of dementia symptoms on their ability to socially engage but sometimes decided to give up socialising when they knew they had dementia. There were negative consequences from social changes being attributed to factors such as choice, rather than dementia

Conclusion Clinicians should ask about social changes in people with dementia. Explaining that these may be due to dementia and considering strategies to overcome them may be beneficial.

\section{INTRODUCTION}

Dementia has major societal and individual impact; in the UK, around 850000 people have dementia $^{1}$ and 670000 people act as primary

\section{Strengths and limitations of this study}

The first in-depth study of how people with dementia and their family carers attribute the social changes that occur in dementia.

- This study includes participants from a range of educational and socioeconomic backgrounds and both carer and patient perspectives.

- The number of participants is relatively small, as is common in in-depth qualitative studies.

- Our findings are limited to mild dementia and people in contact with dementia services.

family carers for them. ${ }^{23}$ Despite a decline in everyday activities, such as withdrawal from previously established social networks, loss of social activities and changes in interpersonal communication styles, being a diagnostic feature of dementia, ${ }^{4}$ carers are less likely to recognise and report social disengagement. ${ }^{5}$ This may be due to misattributing them to other causes, possibly because they are unaware that it is a possible feature of the illness. Clinicians may give less attention to social function changes than other symptoms of dementia, such as cognitive decline, neuropsychiatric symptoms and activities of daily living, and so little attempt may be made to improve social functioning in people with dementia.

Other dementia symptoms, including memory loss, increased dependency on others, ${ }^{6}$ and emotional fluctuation ${ }^{7-10}$ are frequently misattributed or coattributed to other causal factors including the person with dementia having some control of their behaviour. ${ }^{9}{ }^{11-13}$ Carers offer more support when perceiving the person with dementia to have no control over behaviours, including aggression and repetitiveness, ${ }^{14}{ }^{15}$ and less support when they believe they are perceiving them to be purposeful. ${ }^{1617}$ This may be true also about carer attribution of changes to social functioning. 
More social contact has been associated with cognitive improvement in people with early cognitive changes ${ }^{18} 19$ and better quality of life within dementia. ${ }^{20}$ This suggests, despite social functional decline being characteristic of dementia, that there is a possibility that facilitating increased social contact in people with dementia may improve disease outcomes. Social functioning changes can be an early symptom of the condition, so timely recognition of such changes may facilitate earlier access to diagnosis and care. ${ }^{21} 22$ Dementia characteristics are often attributed to normal ageing or other physical, mental and chronic health conditions, ${ }^{7-10}$ leading to missed or delayed diagnoses. ${ }^{21}$ Health problems ${ }^{23} 24$ or

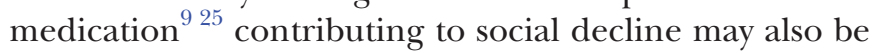
neglected, resulting in missed opportunity to manage treatable factors.

Qualitative research has explored how carers attribute neuropsychiatric symptoms in dementia, ${ }^{13}$ but attribution of social changes by people with dementia and their family carers and how this affects subsequent care is unexplored. In this study, we aimed to identify (1) social changes that occur in dementia, (2) what people with dementia and carers separately attribute these changes to and (3) the consequences, for people with dementia and carers, of these attributions.

\section{METHOD \\ Design}

We conducted a qualitative study using semi-structured interviews to gather detailed information from people with dementia and their family carers, allowing thematic analysis.

\section{Settings}

The study recruited from Camden and Islington National Health Service (NHS) Foundation Trust, which is a UK NHS mental health provider in a socially diverse population covering inner and suburban London. We recruited participants from the 'Memory Services', where patients with suspected dementia are referred for assessment, treatment and ongoing support, including medication and individual and group psychological therapies. Eligible participants were identified by doctors, nurses and psychologists working in these services and were given written information about the study. A researcher contacted interested people at least 48 hours later to provide more information and gain informed consent to participate. Ethical approval for this study was granted from Westminster NRES committee (reference: 15/ LO/0105).

\section{Participants}

We purposively sampled participants to attain diversity in ethnicity and socioeconomic status. We aimed to recruit and interview up to 25 participants or until we reached theoretical saturation.
Inclusion and exclusion criteria for people with dementia

- A clinical diagnosis of dementia of any subtype, with score of above 20 on the mini-mental state examination. ${ }^{26}$

- English language skills adequate to participate in interviews.

- Capacity to give informed consent.

- We excluded people who had comorbid severe physical or mental illness that would prevent them from completing the interview.

\section{Inclusion and exclusion criteria for carers}

- Current, unpaid, main carer, aged over 18 years, who visits the person with dementia a minimum of twice per week.

- English language skills adequate to participate in interviews.

- Capacity to give informed consent.

- We excluded carers who had severe physical or mental illness or dementia.

\section{Data collection and procedure}

We developed a semi-structured interview guide from the literature on social and functional changes in dementia, covering underexplored specific areas. We used case vignettes describing typical social changes related to dementia to introduce the topic. The broad questions included the following:

-What parts of your social life are important to you?

- Which parts of your social life would you regret losing?

- What aspects are important to carers of people with dementia?

-What changes in social life have you noticed?

- When did this change happen?

-What do you think caused it?

All interviews took place in the homes of the participants and lasted between 30 and $70 \mathrm{~min}$. Each participant was interviewed on a single occasion, and patient and carer interviews were conducted separately. Interviews were conducted by two male researchers with no previous acquaintance with any participants: AS, a psychiatrist, and DS, a master's student with a background in psychology. We interviewed the person with dementia and carer separately. We also recorded demographic and clinical information about the participants.

\section{Analysis}

The interviews were audio recorded and transcribed, and we checked the transcriptions for accuracy, also removing any identifying information. Field notes were recorded by one researcher (AS) during the interviews. We then coded the interviews using the qualitative analysis software NVIVO V.9 (QSR International, 2010). Two researchers (AS and DS) separately analysed the transcripts and agreed on a developing coding frame, resolving disagreement with discussion with a third researcher (GL). We used thematic analysis, ${ }^{27}$ in which themes are developed 
Table 1 Demographic and clinical features of participants

\begin{tabular}{|c|c|c|c|}
\hline & & $\begin{array}{l}\text { Person } \\
\text { with } \\
\text { dementia } \\
(\mathrm{n}=9)\end{array}$ & $\begin{array}{l}\text { Carer } \\
(n=9)\end{array}$ \\
\hline & & \multicolumn{2}{|l|}{ Mean (SD) } \\
\hline \multirow{2}{*}{\multicolumn{2}{|c|}{ Age (years) }} & $79(8)$ & $68(11)$ \\
\hline & & n (\%) & \\
\hline Sex & Female & $4(44)$ & $7(78)$ \\
\hline Ethnicity & $\begin{array}{l}\text { White British } \\
\text { White Other } \\
\text { Asian } \\
\text { Afro-Caribbean }\end{array}$ & $\begin{array}{l}4(45) \\
4(44) \\
1(11) \\
0(0)\end{array}$ & $\begin{array}{l}5(56) \\
2(22) \\
1(11) \\
1(11)\end{array}$ \\
\hline Marital status & $\begin{array}{l}\text { Married } \\
\text { Single } \\
\text { Divorced/widowed }\end{array}$ & $\begin{array}{l}5(56) \\
2(22) \\
2(22)\end{array}$ & $\begin{array}{l}7(78) \\
1(11) \\
1(11)\end{array}$ \\
\hline $\begin{array}{l}\text { Employment } \\
\text { status }\end{array}$ & $\begin{array}{l}\text { Retired } \\
\text { Employed } \\
\text { Other }\end{array}$ & $\begin{array}{l}9(100) \\
0(0) \\
0(0)\end{array}$ & $\begin{array}{l}5(56) \\
3(33) \\
1(11)\end{array}$ \\
\hline $\begin{array}{l}\text { Level of } \\
\text { education }\end{array}$ & $\begin{array}{l}\text { O-level or less } \\
\text { A-levels } \\
\text { Higher education }\end{array}$ & $\begin{array}{l}3(33) \\
2(22) \\
4(44)\end{array}$ & $\begin{array}{l}2(22) \\
2(22) \\
5(55)\end{array}$ \\
\hline Occupation & $\begin{array}{l}\text { Managerial/professional } \\
\text { Technical/clerical service } \\
\text { Craft/skilled manual } \\
\text { Elementary occupation }\end{array}$ & $\begin{array}{l}5(56) \\
3(33) \\
0(0) \\
1(11)\end{array}$ & $\begin{array}{l}5(56) \\
3(33) \\
1(11) \\
0(0)\end{array}$ \\
\hline Diagnosis & $\begin{array}{l}\text { Alzheimer's } \\
\text { Mixed dementia } \\
\text { Other }\end{array}$ & $\begin{array}{l}6(67) \\
2(22) \\
1(11)\end{array}$ & \\
\hline $\begin{array}{l}\text { Time since } \\
\text { diagnosis }\end{array}$ & $\begin{array}{l}<6 \text { months } \\
6-12 \text { months } \\
>12 \text { months }\end{array}$ & $\begin{array}{l}6(67) \\
2(22) \\
1(11)\end{array}$ & \\
\hline $\begin{array}{l}\text { Relationship } \\
\text { carer }\end{array}$ & $\begin{array}{l}\text { Spouse/partner } \\
\text { Parent/child } \\
\text { Other (friend) }\end{array}$ & $\begin{array}{l}5(56) \\
1(11) \\
3(33)\end{array}$ & \\
\hline
\end{tabular}

based on those arising from the data and others from theory and previous research findings. Recruitment, data collection and analysis took place concurrently, and we judged that theoretical saturation had been reached when no further attributional themes arose. We did not show transcripts back to participants and have not sought feedback from participants on study findings.

\section{RESULTS}

The 18 recruited participants (nine people with dementia and nine carers) represented a range of demographic and clinical characteristics (table 1). No eligible participants refused to take part. The mean age of the people with dementia was 79 (SD 8) years, and they were predominantly white British or from other white ethnic groups. The majority were currently or previously had been married, all were retired and they had a variety of educational backgrounds. Two-thirds had Alzheimer's disease and had received their diagnosis within
Table 2 The five core themes of attributions toward changes in social activity

\section{Overarching}

themes

Specific subthemes

\begin{tabular}{|c|c|c|}
\hline \multirow[t]{3}{*}{ Carer factors } & Carer beliefs & Difficulty finding time \\
\hline & & $\begin{array}{l}\text { Not wanting to } \\
\text { burden patient with } \\
\text { their own concerns }\end{array}$ \\
\hline & Patient beliefs & $\begin{array}{l}\text { Belief that carer } \\
\text { would worry about } \\
\text { their ability to be } \\
\text { independent }\end{array}$ \\
\hline \multirow[t]{3}{*}{ Patient factors } & Carer beliefs & $\begin{array}{l}\text { That patient makes } \\
\text { excuses for avoiding } \\
\text { social situations }\end{array}$ \\
\hline & Patient beliefs & $\begin{array}{l}\text { Embarrassment at } \\
\text { social faux-pas }\end{array}$ \\
\hline & & $\begin{array}{l}\text { Inability to keep track } \\
\text { of conversations with }\end{array}$ \\
\hline
\end{tabular}

\begin{tabular}{lll} 
External factors & $\begin{array}{l}\text { Carer and patient } \\
\text { beliefs }\end{array}$ & $\begin{array}{l}\text { Reduced social } \\
\text { network due to } \\
\text { bereavement or } \\
\text { isolation }\end{array}$ \\
Physical health & $\begin{array}{l}\text { Carer and patient } \\
\text { beliefs }\end{array}$ & $\begin{array}{l}\text { Age-related frailty } \\
\text { or specific physical } \\
\text { illness }\end{array}$ \\
\hline Patient beliefs & Carer beliefs & $\begin{array}{l}\text { Dementia diagnosis } \\
\text { allowed access to } \\
\text { support services } \\
\text { Insight into condition } \\
\text { increased acceptance } \\
\text { of social limitations } \\
\text { Inhibited by stigma of } \\
\text { dementia }\end{array}$ \\
\hline
\end{tabular}

the previous 6 months. Most of the nine carers were the spouse or close friend of a person with dementia. They were younger than the people with dementia (mean 68 (SD 11) years), and some continued to be in employment.

The analysis revealed several changes in social activity that were recognised by people with dementia or carers. These included the broad areas of giving up on previously enjoyed hobbies or activities; no longer independently arranging social events; struggling with social communication at social events, such as losing track of conversations, or not initiating conversation; and irritability at friends or family. When carers or people with dementia identified recent social changes, we sought their attribution of this change. Our analysis of participants' explanation of these social changes revealed five overarching attribution themes: carer factors, choices of the person with dementia, external factors, physical health and dementia (table 2). 


\section{Carer factors}

Carer factors included carers acknowledging their own difficulty in supporting the person with dementia in engaging and maintaining engagement in social activities. People with dementia also expressed their concerns that their illness burdens their family members with stress and obligations.

Carers told us that more time and commitment are required to support someone with dementia in preparing for social activities, such as leaving the house to visit people or going to the cinema. This, they said, made it more difficult to provide support to their relative to stay socially active. One carer, a friend of a person with dementia who lives alone, stated that this led to them giving up on their attempts to encourage their friend to be socially active.

Attribution: "Now we have to come here, make sure she's got her keys, make sure she's got her gloves, make sure she's got everything, make sure that she has got her phone ... and then you have to deliver her back so it gets to the point, and this is a social thing, it gets to the point when sometimes you think-I just don't have the energy for that."

Consequence: "So you don't invite her to things, so that's how it affects her social life."

(C9A-a woman in her 70s, friend of a person with dementia)

A person with dementia, who was aware of his frailty and vulnerability, told us that, because he has fallen when out on his own before, he feels he cannot go out alone because his family would worry about his safety. This worry led to him isolating himself more, being more reluctant to go out alone.

Attribution: "Because I wouldn't go alone ... I think (carer name) wouldn't approve ... I think she worries ... that I faint or that I would stumble ... and I fell a couple of times. She would think I need help."

Consequence: "I am less likely to go now. I wouldn’t go alone."

P5-a 92-year-old white man with Alzheimer's disease

Some carers told us about how their own concern for the person with dementia would act as a barrier to disclosing personal information, therefore affecting their previously close personal relationships. One carer told us that she did not want to engage in conversation about her personal life because she felt that her mother may now be unable to cope with distressing information.

Attribution: 'You know, I've had my relationship break down ... and I didn't feel like I could speak to mum about it because I didn't want her to get upset."

Consequence: "So I stopped talking to her about things ... I don't talk to her about anything at all."

C3-a 43-year-old white British woman, daughter of a person with dementia

\section{Choices of the person with dementia}

The patient or carer sometimes attributed the reduced social engagement to an active choice of the person with dementia-carers often attributed social change to the person with dementia's premorbid personality characteristics and people with dementia described embarrassment which inhibited their social relationships.

Carers frequently stated that the person with dementia just did not want to interact with others and would find reasons to justify this. Some carers described these as 'excuses' which led to the person with dementia becoming more socially isolated and less socially stimulated with others.

Attribution: "I think sometimes it's easier for him to switch off if he couldn't hear he didn't have to engage ... I think it's deliberate. I think sometimes it's easier not to hear the conversation or to pretend you don't hear the conversation."

Consequence: "He removes himself now. He more and more didn't want to see them or made excuses not to see them ... so you don't have to engage in it when you are tired I think."

C6-a 56-year-old Afro-Caribbean woman, wife of person with dementia

One patient told us that distress caused by their symptoms, which they attributed to stress, affected their ability to socially engage with friends or family as they had previously done. They stated that they would actively find alternative explanations for dementia-related behaviour when with friends, rather than acknowledging these difficulties openly.

Attribution: "And I, as I say, I put it all down to stress, which I believed, I wasn't hiding anything. I thought it was stress and my doctor did as well. But we went and had the scans and I got the diagnosis."

Consequence: "I covered things up... I'd make excuses if I had said something for the third time."

P7-a 66-year-old white British woman with Alzheimer's disease

Embarrassment at declining memory and cognitive function was frequently a cause for participants avoiding social situations. One woman with dementia told us that her concerns over how people would perceive her directly affected whether she chose to see friends. This concern led to her becoming more withdrawn.

Attribution: "I don't know what happened to me. I just took it to heart, I think. And I thought everybody will be looking at me different. Everybody will be taking pity on me. And all that. And I wasn't very confident myself at all before that, but I was getting by, you know?"

Consequence: "Well I stopped going altogether ... I stopped going to see my friend. We used to go 
to bingo and everything together ... I would make excuses not to see them."

P3-a 75-year-old white Irish woman with Alzheimer's disease

One person with dementia reported that they were unable to retain as much information and needed to make notes to keep track of information. They did not directly attribute this change to dementia, and it led them to withdraw from their volunteer work as they felt incapable of performing at their previous level, thereby stopping a previously important social activity.

Attribution:

"But I found that I was needing to write down, and I was beginning to need to write down, more and more and more ... Yes. I was finding it difficult to retain all the information ... Yes, because of this need to write everything down because I couldn't retain a long conversation."

Consequence:

"And so, I just decided I had to stop being a volunteer

... because I wasn't doing it as well as I used to."

P7-a 66-year-old white British woman with Alzheimer's disease

\section{External factors}

Participants frequently attributed social change to factors which were beyond the control of either patient or carer. This was usually related to reduced number of family and friends available with whom to interact, including bereavement.

Attribution:

"As I say, being old, a lot of them, they've all gone. They've passed on.”

\section{Consequence:}

"He is more quiet. I've noticed him, not wanting to go out so much anymore."

C4-a 73-year-old white British woman, wife of person with dementia

Attribution:

"Well all his friends have died, for one thing, and that has nothing to do with his Alzheimer's."

\section{Consequence:}

"It's made a big difference for him. I think a lot of his social life revolved around (wife), and she's died now, so he is less social now."

C5-a 76-year-old white British woman, sister-in-law to person with dementia

One participant, originally from USA, commented that their social network has become increasingly dispersed across different countries.

Attribution:
"Mainly because most of my friends are living in other parts of the world."

Consequence:

"I am not as social as I used to be."

P9-a 77-year-old white American woman with Alzheimer's disease

\section{Physical health}

Decline in physical health was frequently identified by both people with dementia and carers as a cause for difficulties in maintaining social engagement. While some carers had perceived that their relative had used their physical health problems as an 'excuse' to avoid social activities, more often, this was described as an understandable barrier to social activity, and we found agreement within dyads about this as a cause of restricted activity.

Attribution:

"Because of my arthritis and mobility problems. That is because simply of my mobility problems."

Consequence:

"I have to skip it. I don't do it as much, I am restricted."

P1-a 85-year-old south Asian man with Alzheimer's disease

Attribution:

"Because of his physical problems."

Consequence:

"He can't go out. We are not taking as many trips as we used to, so that sort of thing restricts his activities and his interests."

C1-a 73-year-old Indian woman, wife of person with dementia

Attribution:

"He will be 80 this year, he's got Parkinson's, he can't walk properly. If he was a younger man it would be different."

\section{Consequence:}

"He hasn't got the energy to do it. He doesn't feel he wants to do it anymore."

C6-a 56-year-old Afro-Caribbean woman, wife of person with dementia

\section{Dementia}

The attribution of social difficulties to dementia had diverse effects on the person with dementia's ability to stay socially active. For some of the patients, the diagnosis itself was distressing and associated with stigma, but for carers, the process of receiving the diagnosis was cathartic and dementia could explain previously confusing behaviour.

One participant described their devastation at being told, in their early $70 \mathrm{~s}$, that they had dementia and the negative consequences of this knowledge. 
Attribution:

"I think it's Alzheimer's. When I was diagnosed, everything went downhill. I just took it to heart."

Consequence:

"Once I was diagnosed, I gave it all up."

P3-a 75-year-old white Irish woman with Alzheimer's disease

However, this participant's daughter reported that later acceptance of the diagnosis, assisted by psychological therapy, which was provided by the local NHS dementia service, had led to positive consequences.

Consequence:

"She has now accepted the diagnosis too, and has started to talk to people again. We talk about everything now, and are opening up a lot more."

C3-a 43-year-old white British woman, daughter to a person with dementia

Receiving a diagnosis of dementia also provided some participants with access to group sessions of cognitive stimulation therapy, which included reminiscence. Carers noted that these sessions improved the confidence of their relative.

Consequence:

"They were talking about older times and everything, he seemed to enjoy it ... when they started talking about older times, they could open up."

C4-a 73-year-old white British woman, wife of person with dementia

The friend of a person with dementia noted that their recognition of the social consequences of dementia from observing their own mother's experience of the condition had led to the positive consequence of both the patient and them making efforts to maintain social interaction.

Attribution:

"Her mother had dementia too, so we discovered through her that you lose the ability to entertain yourself."

\section{Consequence:}

"And so (name) actually wants to have more people around her so that she doesn't lose the social aspect

... a greater desire to be around people."

C9B - a 73-year-old white man, carer of and friend to the person with dementia

One person with dementia told us of dementia causing difficulty in recalling details of television programmes, which would previously be a topic of conversation with friends and family. He identified that this made it more difficult to sustain conversation and that he would be unable to discuss topics of interest.

Attribution:
"I couldn't keep up with it ... I can't even remember some of, who followed whom, and which emperor became something else."

\section{Consequence:}

"It makes my conversation with other people gets less and less. You know, because I can't talk about things with them ... if I saw somebody knew, I don't think that I'd be able to discuss it with them or what."

P5—a 92-year-old white man with Alzheimer's disease

\section{DISCUSSION}

Our study provides insight into how people with dementia and carers attribute the changes in social functioning that have occurred in people with dementia, along with the accompanying consequences or actions related to these attributions. In this first study exploring this area, we report that patients and carers frequently explain social function changes, which are at least partly a consequence of dementia, to many factors but often not to dementia itself. When dementia is not a recognised factor in these changes, negative consequences, such as impaired relationships and reduced social activity, are more likely to ensue. People with dementia and carers who attribute social changes to dementia frequently describe more acceptance and making adjustments that maximised their social function.

We found that patients and carers identified several reasons as to why they believed the social changes in the person with dementia had occurred. Some of these factors have previously been reported to be related to cognitive or neuropsychiatric symptoms, including choices of the patient, ${ }^{9} 1213$ physical health, ${ }^{52428-30}$ normal ageing 8103132 and internal factors of the carers. ${ }^{33} 34$ Although our results show similarity with previous literature in terms of the range of attributions reported, our study is the first to find that these are made to explain social changes.

We found that many of our participants attributed social changes to dementia itself, which shows similarity with previous literature. ${ }^{35}$ Consistent with previous findings, our study found some evidence that positive actions followed when dementia was identified as a factor in social changes, including earlier access to support, and actively seeking out company for socialising. Our results therefore support the self-regulation theory, ${ }^{36}$ which proposes that coping becomes easier and more successful when the illness is identified. We also report that when social changes were attributed to dementia, there was a more positive patient-carer relationship, which contrasts with a study from 20 years ago. ${ }^{37}$ Our differing results could be explained by there being a greater understanding of dementia now, with improved education and awareness of the effects of dementia. ${ }^{38}$ Furthermore, there is better postdiagnostic support, and for example, we found that carers believed that attendance at cognitive stimulation therapy groups ${ }^{39}$ aided confidence and social engagement. 
We found that carers offered more explanations for social changes than the people with dementia did, which may be due to dementia impairing abstract thinking. ${ }^{9}$ Carers may also offer more alternative explanations because they may be struggling to accept the diagnosis, perhaps due to stigma, ${ }^{6}$ and so seek other explanations. Alternative explanations may not be attributional errors ${ }^{40}$; it may be more useful to look at these with a more multifactorial approach in order to better understand changes in dementia, such as assessing whether a person has become socially withdrawn because of physical illness, pain and depression. This is a more appropriate and consistent way and follows the person-centred approach advocated for the care of elderly people by the $\mathrm{WHO}^{41}$ and UK Government. ${ }^{42}$ Our research does, however, highlight the importance in recognising dementia itself to be a co-factor in these changes as, when it is, more positive actions follow.

\section{Strengths and limitations}

This is the first study providing insight into the attributions carers and patients make of social changes in people with dementia. Additionally, it is the first study exploring the links between these attributions and subsequent actions. We used appropriate methodology and analytic approach for qualitative research ${ }^{43}$ and interviewed a diverse range of educational, ethnic and socioeconomic backgrounds, as well recruiting spousal dyads and parents and children.

Although the number of participants is relatively low, this is acceptable for qualitative research that aims to gain a detailed understanding of a concept from a group sharing similar properties. While participants continued to describe a range of previously enjoyed social activities, our latter interviews did not yield new or different attributions for reduced engagement in them, indicating we had reached theoretical saturation regarding our primary objective, in our study sample. Our conclusions are limited to carers and people with mild dementia, but people with moderate or severe dementia may be less able to think abstractly and give complex views, ${ }^{44}$ which was crucial for our study. Furthermore, our results may be specific to those based in urban settings and people whose dementia has been diagnosed recently by a memory service. Participants may have been reluctant to talk openly about sensitive topics, such as personal relationships. However, we do not feel this interviewer influence occurred in our study, as patients did talk openly about sensitive topics.

\section{Clinical implications and further research}

The results of this study inform dementia care in several ways. As our research found positive consequences when patients and their carers knew more about the social changes that could be expected in dementia, it suggests that more education for patients and carers would be beneficial. As is usual practice for the assessment of neuropsychiatric or cognitive symptoms, clinicians would need to actively enquire about social function changes and possible contributors other than dementia, for example, pain, depression and premorbid personality; provide information about dementia-related changes; and suggest strategies such as modifications to carer behaviour and social interventions, for example, day centres or support groups. This approach fits with the 'biopsychosocial model $^{45}$ used in older adults' medicine and psychiatry, in which holistic care is provided by attending to physical, psychological and social needs. As people with dementia frequently lack insight into their condition and the cognitive and behavioural symptoms impair their ability to manage or change their own behaviour, the input of carers or healthcare professionals is frequently required to make lasting and meaningful improvements to the social function of a person with dementia (the 'enriched environment' advocated by Kitwood ${ }^{46}$ ).

Participants in our study reported beneficial consequences from cognitive stimulation therapy groups, including increased social engagement and reduced isolation. ${ }^{47}$ Our study showed that patients found these groups beneficial for their social activity, so they could act as a gateway to accessing or creating more frequent and long-lasting social groups and thus improve their quality of life and the social consequences of cognitive stimulation therapy should be studied in future research. Additionally, there may be a role for new interventions specifically targeting improved social function to improve quality of life and to study how this links with other clinical outcomes. There is consistent evidence that social activity delays cognitive decline in normal ageing older people ${ }^{48-50}$ and there is evidence that it may prevent progression from mild cognitive impairment to dementia ${ }^{51}$; so it is conceivable that social activity in dementia may reduce cognitive decline by maintaining cognitive reserves and may help non-cognitive symptoms of dementia.

\section{CONCLUSIONS}

Social changes in dementia are less recognised as a symptom of dementia by both carers and people with dementia. When dementia is not acknowledged as a factor behind the social changes, more negative consequences including social isolation can occur. When dementia is recognised as a factor, more positive actions follow, including positive family relationships. While dementia is rarely the sole cause of social changes, we conclude that clinicians should be alert for the effect of dementia on social decline and encourage understanding in people with dementia and carers.

Twitter@atsommerlad

Acknowledgements We would like to thank the people with dementia and their family carers for their involvement in the study and to staff at Camden and Islington NHS Foundation Trust who helped with recruitment of study participants.

Contributors DS,GL and AS conceived and designed the study. GL and AS obtained ethical approval for the conduct of the study. DS and AS conducted interviews and performed analysis. All authors contributed substantially to drafting the article and 
revising it critically for intellectual content and gave final approval to the submitted manuscript.

Funding This research received no specific grant from any funding agency in the public, commercial or non-profit searches.

Competing interests All authors have completed the ICMJE uniform disclosure form at www.icmje.org/coi_disclosure.pdf and have nothing to declare.

Patient consent All participants gave written informed consent to take part in the study.

Ethics approval Ethical approval for this study was granted from Westminster NRES committee (reference: 15/LO/0105).

Provenance and peer review Not commissioned; externally peer reviewed.

Data sharing statement № additional data are available.

Open Access This is an Open Access article distributed in accordance with the Creative Commons Attribution Non Commercial (CC BY-NC 4.0) license, which permits others to distribute, remix, adapt, build upon this work non-commercially, and license their derivative works on different terms, provided the original work is properly cited and the use is non-commercial. See: http://creativecommons.org/ licenses/by-nc/4.0/

(C) Article author(s) (or their employer(s) unless otherwise stated in the text of the article) 2017. All rights reserved. No commercial use is permitted unless otherwise expressly granted.

\section{REFERENCES}

1. Prince M, Knapp M, Guerchet M, et al. Dementia UK: update. Alzheimer's Society 2014.

2. Lakey L, Chandaria K, Quince C, et al. Dementia 2012: A national challenge. London: Alzheimer's Society, 2012:68-73.

3. Knapp MBN, Dixon J, Damant J, et al. Independent assessment of improvements in dementia care and support since 2009. London: Policy Innovation Research Unit and NIHR School for Social Care Research. London School of Economics; London School of Hygiene and Tropical Medicine, 2014.

4. Organization $\mathrm{WH}$. The ICD-10 classification of mental and behavioural disorders: diagnostic criteria for research. 993

5. Roger KS. Understanding social changes in the experience of dementia. Alzheimer's Care Today 2006;7:185-93.

6. Green SK. Senility versus wisdom: the meaning of old age as a cause for behavior. Basic App/ Soc Psych 1984;5:105-10.

7. Pollitt PA. Dementia in old age: an anthropological perspective. Psychol Med 1996;26:1061-74.

8. Whitehouse R, Chamberlain P, Tunna K. Dementia in people with learning disability: a preliminary study into care staff knowledge and attributions. Br J Learn Disabil 2000;28:148-53.

9. Paton J, Johnston K, Katona C, et al. What causes problems in Alzheimer's disease: attributions by caregivers. A qualitative study. Int J Geriatr Psychiatry 2004;19:527-32.

10. Clare L, Goater T, Woods B. Illness representations in early-stage dementia: a preliminary investigation. Int J Geriatr Psychiatry 2006;21:761-7.

11. Weiner B. A cognitive (attribution)-emotion-action model of motivated behavior: an analysis of judgments of help-giving. J Pers Soc Psychol 1980;39:186-200.

12. Martin-Cook K, Remakel-Davis B, Svetlik D, et al. Caregiver attribution and resentment in dementia care. Am J Alzheimers Dis Other Demen 2003:18:366-74.

13. Hinton L, Chambers D, Velásquez A. Making sense of behavioral disturbances in persons with dementia: Latino family caregiver attributions of neuropsychiatric inventory domains. Alzheimer Dis Assoc Disord 2009;23:401.

14. Emerson E, Hastings R, Values MP. Attitudes and service ideology. Severe learning disabilities and challenging behaviours. Springer, 1994:p. 209-31.

15. Hastings RP, Tombs AK, Monzani LC, et al. Determinants of negative emotional reactions and causal beliefs about self-injurious behaviour: an experimental study. J Intellect Disabil Res 2003;47:59-67.

16. Tarrier N, Barrowclough C, Ward J, et al. Expressed emotion and attributions in the carers of patients with Alzheimer's disease: the effect on carer burden. J Abnorm Psychol 2002;111:340-9.

17. Wearden AJ, Tarrier N, Barrowclough C, et al. A review of expressed emotion research in health care. Clin Psychol Rev 2000;20:633-66.

18. Marioni RE, Valenzuela MJ, van den Hout $A$, et al. Active cognitive lifestyle is associated with positive cognitive health transitions and compression of morbidity from age sixty-five. PLoS One 2012; 7:e50940.

19. Marioni RE, van den Hout A, Valenzuela MJ, et al. Active cognitive lifestyle associates with cognitive recovery and a reduced risk of cognitive decline. J Alzheimers Dis 2012;28:223-30.

20. Livingston G, Cooper C, Woods J, et al. Successful ageing in adversity: the LASER-AD longitudinal study. J Neurol Neurosurg Psychiatry 2008;79:641-5.

21. Newens AJ, Forster DP, Kay DW. Referral patterns and diagnosis in presenile Alzheimer's disease: implications for general practice. $\mathrm{Br} J$ Gen Pract 1994;44:405-7.

22. Hurt CS, Burns A, Brown RG, et al. Why don't older adults with subjective memory complaints seek help? Int J Geriatr Psychiatry 2012;27:394-400.

23. Levkoff $S$, Wetle T. Clinical decision making in the care of the aged. $J$ Aging Health 1989;1:83-101.

24. Ortiz F, Fitten LJ, Cummings JL, et al. Neuropsychiatric and behavioral symptoms in a community sample of Hispanics with Alzheimer's disease. Am J Alzheimers Dis Other Demen 2006;21:263-73.

25. Hinton L, Franz CE, Yeo G, et al. Conceptions of dementia in a multiethnic sample of family caregivers. J Am Geriatr Soc 2005;53:1405-10.

26. Folstein MF, Folstein SE, McHugh PR. 'Mini-mental state': a practical method for grading the cognitive state of patients for the clinician. $J$ Psychiatr Res 1975;12:189-98.

27. Braun V, Clarke V. Using thematic analysis in psychology. Qual Res Psychol 2006;3:77-101.

28. Hinton L, Franz CE, Reddy G, et al. Practice constraints, behavioral problems, and dementia care: primary care physicians' perspectives. J Gen Intern Med 2007;22:1487-92.

29. Boise L, Neal MB, Kaye J. Dementia assessment in primary care: results from a study in three managed care systems. J Gerontol A Biol Sci Med Sci 2004;59:M621-M626.

30. Ganguli M, Rodriguez E, Mulsant B, et al. Detection and management of cognitive impairment in primary care: the Steel Valley Seniors Survey. J Am Geriatr Soc 2004;52:1668-75.

31. Helmes E, McKirdy T, Caltabiano M. Help-seeking for dementia among older adults: an application of the self-regulatory model. Australasian J on Ageing 2010:29-16.

32. Boise L, Camicioli R, Morgan DL, et al. Diagnosing dementia: perspectives of primary care physicians. Gerontologist 1999;39:457-64.

33. Spijker A, Vernooij-Dassen M, Vasse E, et al. Effectiveness of nonpharmacological interventions in delaying the institutionalization of patients with dementia: a meta-analysis. J Am Geriatr Soc 2008;56:1116-28.

34. Williamson GM, Shaffer DR, Schulz R. Activity restriction and prior relationship history as contributors to mental health outcomes among middle-aged and older spousal caregivers. Health Psychol 1998;17:152-62.

35. Feldman L, Wilcock J, Thuné-Boyle I, et al. Explaining the effects of symptom attribution by carers on help-seeking for individuals living with dementia. Dementia 2017;16.

36. Leventhal H, Nerenz D, Steele D. Illness representations and coping with health threats. In: Baum A, Taylor SE, Singer JE, Handbook of Psychology and Health. Hillsdale: NJ:Erlbaum, 1984.

37. Sweeting HN. Caring for a relative with dementia: anticipatory grief and social death: University of Glasgow. 1991.

38. Do H. Living well with dementia: a national dementia strategy: department of Health. 2009.

39. Knapp M, Thorgrimsen L, Patel A, et al. Cognitive stimulation therapy for people with dementia: cost-effectiveness analysis. $\mathrm{Br} J$ Psychiatry 2006;188:574-80.

40. Polk DM. Communication and family caregiving for Alzheimer's dementia: linking attributions and problematic integration. Health Commun 2005;18:257-73.

41. Organization WH, Association WP. Reducing stigma and discrimination against older people with mental disorders. 2002.

42. Mackenzie J, Bartlett R, Downs M. Moving towards culturally competent dementia care: have we been barking up the wrong tree? Rev Clin Gerontol 2005;15:39-46.

43. Lee N, Saunders J, Goulding C. Grounded theory, ethnography and phenomenology: a comparative analysis of three qualitative strategies for marketing research. Eur J Mark 2005;39:294-308.

44. Train G, Nurock S, Kitchen G, et al. A qualitative study of the views of residents with dementia, their relatives and staff about work practice in long-term care settings. Int Psychogeriatr 2005;17:237-51.

45. Spector A, Orrell M. Using a biopsychosocial model of dementia as a tool to guide clinical practice. Int Psychogeriatr 2010;22:957-65. 
46. Kitwood T. Towards a theory of dementia care: the interpersonal process. Ageing Soc 1993;13:51-67.

47. NICE. Dementia: Supporting people with dementia and their carers in health and social care. NICE Guidlines 2016.

48. James BD, Wilson RS, Barnes LL, et al. Late-life social activity and cognitive decline in old age. $J$ Int Neuropsychol Soc 2011;17:998-1005.
49. Barnes LL, Mendes de Leon CF, Wilson RS, et al. Social resources and cognitive decline in a population of older African Americans and whites. Neurology 2004;63:2322-6.

50. Bassuk SS, Glass TA, Berkman LF. Social disengagement and incident cognitive decline in community-dwelling elderly persons. Ann Intern Med 1999;131:165-73.

51. Hughes TF, Flatt JD, Fu B, et al. Engagement in social activities and progression from mild to severe cognitive impairment: the MYHAT study. Int Psychogeriatr 2013;25:587-95. 